http://jmscr.igmpublication.org/home/

ISSN (e)-2347-176x ISSN (p) 2455-0450

crossref DOI: https://dx.doi.org/10.18535/jmscr/v7i11.170

Journal Of Medical Science And Clinical Research

\title{
The Milan System for Reporting Salivary Gland Cytopathology (MSRSGC)
}

\section{Authors \\ Dr Sumana Sindhuram $V^{1}$, Dr Roopashree $\mathbf{G}^{2^{*}}$, Dr Bharathi $\mathbf{M}^{3}$}

${ }^{1}$ Assistant Professor, Department of Pathology, Mysore Medical College and Research Centre, Mysore

${ }^{2}$ Postgraduate Student, Department of Pathology, Mysore Medical College and Research Centre, Mysore

${ }^{3}$ Professor and Head, Department of Pathology, Mysore Medical College and Research Centre, Mysore

*Corresponding Author

\section{Dr Roopashree G}

Postgraduate Student, Department of Pathology, Mysore Medical College and Research Centre, Mysore

Abstract
Background: FNA is a cost-effective and minimally invasive diagnostic tool for sampling salivary gland
lesions. However due to intra-tumoral heterogeneity and frequent overlapping of cyto-morphologic
features precise subtyping of neoplasms can be challenging. To address this, International panel of
experts under the joint effort of the American society of cytopathology and the International academy of
cytology developed the MSRSGC.
Methodology: 356 salivary gland FNA samples were retrospectively analysed and re-categorised into 6
categories of the Milan system. Histopathology diagnoses were retrieved wherever available. Overall
ROM were calculated for each category.
Results: On re-categorising into the Milan system, 62 cases were assigned to non-diagnostic category
(17.4\%), 67 to non-neoplastic category (18.8\%), 48 as Atypical (13.5\%), 101 as benign neoplasms
(28.4\%), 35 to the salivary gland neoplasm of uncertain malignant potential (9.8\%), 16 as suspicious for
malignancy (4.5\%) and 27 to the malignant category (7.6\%).The ROM for above mentioned category
were $30 \%, 7.1 \%, 14.2 \%, 3 \%, 31 \%, 67 \%$ and $95.2 \%$ respectively.
Conclusion: MSRSGC provides uniform reporting system for salivary gland cytopathology which helps to
reduce reporting ambiguities and thus improves overall patient care.
Keywords: Fine-needle aspiration; Milan system for reporting salivary gland cytopathology (MSRSGC);
Risk of malignancy (ROM).

\section{Introduction}

Salivary gland neoplasm comprise approximately $6.5 \%$ of the lesions sampled in the head and neck, out of which approximately $40 \%$ are malignant ${ }^{1}$. A multimodal approach is required as a part of initial diagnostic work-up for salivary gland nodules. However, to finalise the malignant potential of a lesion, fine-needle aspiration (FNA) remains the preferred diagnostic test ${ }^{1-9}$.
Fine needle aspiration (FNA) of salivary gland is a cost-effective and minimally invasive diagnostic technique in guiding the management of superficial masses $^{10-13}$.

Despite the above mentioned advantages, there exist few limitations, including the lack of architecture and cellular complexity of salivary gland neoplasms encountered among the same subtypes and even within an individual tumor ${ }^{17-19}$. 
In an attempt to address some of these limitations of salivary gland FNA a group of

International pathologists proposed a uniform system known as The Milan system for reporting salivary gland cytopathology (MSRSGC) ${ }^{14}$.

Similar to analogous reporting schemes, like the Bethesda System for Reporting Thyroid Cytopathology, this classification system considers the reporting ambiguities inherent to salivary gland pathology, while also risk stratifying lesions, providing a clinical useful guidelines regarding its management ${ }^{16}$.The MSRSGC is composed of seven diagnostic categories: non-diagnostic, non-neoplastic, atypia of undetermined significance, benign neoplasm, salivary gland neoplasm of uncertain malignant potential, suspicious for malignancy, and malignant.

As the MSRSGC is still in its infancy, additional studies are needed to evaluate the effectiveness of this classification system ${ }^{15}$. The main objective of this study was to assess the diagnostic accuracy of salivary gland FNAs using the Milan System and evaluate the MSRSGC as a tool for risk assessment.

\section{Materials and Methods}

FNA specimens from salivary gland lesions that were registered from January 2016 to September 2018 in the cytology department at Mysore medical college and research institute were retrieved. Oral informed consent was obtained from each patient before routine FNA of salivary gland lesions. FNA procedure were performed by trained cytopathologist.

Major and minor salivary gland swellings, including intraoral lesions, were aspirated via direct percutaneous or trans-oral route with 23-27gauge needle. Smears were stained with haematoxylin and eosin stains in all cases for immediate on-site evaluation, and few of the direct smears were stained with the Papanicolaou stain following alcohol fixation. All data related to cytological examination, history, clinical examination and investigations were collected.
FNA diagnoses were retrospectively classified according to the Milan system as follows: NonDiagnostic (ND), Non-Neoplastic (NN), Atypia of Undetermined Significance (AUS), Benign Neoplasm (BN), Salivary gland neoplasm of Uncertain Malignant Potential (SUMP), Suspicious for Malignancy (SM), or Malignant (M).

Histologic diagnoses of surgical specimens were categorized as Non-Neoplastic, Benign Neoplasm and Malignant. Pre and post-operative categorizations were compared to calculate the risk of neoplasm (RON) and risk of malignancy (ROM).Overall accuracy, specificity and sensitivity of the diagnostic categories were calculated.

\section{Results}

A total of 356 FNA specimens were identified between January 2016 and September 2018 which included 189 females and 167 males (female:male ratio of 1.1:1) with an average age of 52 years (range 12-90 years). The most frequent site of involvement was the parotid gland (232/356, $65.1 \%$ ), followed by the submandibular gland $(118 / 356,33.1 \%)$, and last the minor salivary glands $(6 / 356,1.7 \%)$.

The pre-operative cytology classifications and histologic follow-up are summarized in (Table 1).

For the FNA cases with surgical follow-up, the risks of neoplasm and malignancy were calculated for each of the Milan System diagnostic categories (Table 1). The most common benign and malignant diagnoses in each category are listed in (Table 2).

Discordance between FNA and histologic diagnoses was observed in 5 cases. In the nonneoplastic FNA group, 1/14 (7.1\%) case was ultimately diagnosed as lipoma and 1/14 (7.1\%) were diagnosed as lymphoma. Among cases called benign neoplasm on FNA, 2/67 (3.0\%) were reported to be malignant on resection which included cases of adenoid cystic carcinoma and mucoepidermoid carcinoma. 
Finally, of cases called malignant on FNA, 1/21 (4.8\%) was Warthin tumor on histologic followup.

Malignancies represented by the AUS category included lymphoma (2), mucoepidermoid carcinoma (2), squamous cell carcinoma (1) and adenoid cystic carcinoma (1). Non-neoplastic entities included lymphoepithelial cyst (4), benign salivary gland tissue (6), sialadenitis (2) and reactive lymphoid tissue (2). The overall sensitivity, specificity, negative predictive value (NPV), and positive predictive value (PPV) were $82.4 \%, 96.2 \%, 89.4 \%$, and $100 \%$, respectively.

Table 1: Histopathology follow-up and risk estimation of salivary gland lesions on FNA cytology using the Milan system

\begin{tabular}{|l|c|c|c|c|c|c|c|c|}
\hline & & ND & NN & AUS & BN & SUMP & SM & M \\
\hline Cytology Diagnosis & $\begin{array}{c}\text { Total } \\
\mathrm{n}=356\end{array}$ & $62(17.4 \%)$ & $\begin{array}{c}67(18.8 \\
\%)\end{array}$ & $48(13.5 \%)$ & $101(28.4 \%)$ & $35(9.8 \%)$ & $16(4.5 \%)$ & $27(7.6 \%)$ \\
\hline & $\begin{array}{c}\text { Non-neoplastic } \\
\mathrm{n}=37(18.9 \%)\end{array}$ & $2(20.0 \%)$ & $\begin{array}{c}12(85.7 \\
\%)\end{array}$ & $14(33.3 \%)$ & $8(11.9 \%)$ & $0(0 \%)$ & $1(8.3 \%)$ & $0(0 \%)$ \\
\hline $\begin{array}{l}\text { Surgical follow-up } \\
\text { n=195(54.8\%) }\end{array}$ & $\begin{array}{c}\text { Benign neoplasm } \\
\mathrm{n}=109(56 \%)\end{array}$ & $5(50.0 \%)$ & $1(7.1 \%)$ & $22(52.4 \%)$ & $57(85.0 \%)$ & $20(69 \%)$ & $3(25.0 \%)$ & $1(4.8 \%)$ \\
\hline & $\begin{array}{c}\text { Malignant } \\
\mathrm{n}=49(25.1 \%)\end{array}$ & $3(30.0 \%)$ & $1(7.1 \%)$ & $6(14.3 \%)$ & $2(3.0 \%)$ & $9(31.0 \%)$ & $8(66.7 \%)$ & $20(95.0 \%)$ \\
\hline Risk of neoplasm & & $80.0 \%$ & $14.3 \%$ & $66.7 \%$ & $88.1 \%$ & $100 \%$ & $91.2 \%$ & $100 \%$ \\
\hline Risk of malignancy & & $30.0 \%$ & $7.1 \%$ & $14.2 \%$ & $3.0 \%$ & $31.0 \%$ & $66.7 \%$ & $95.2 \%$ \\
\hline
\end{tabular}

Abbreviations: ND-Non-diagnostic; NN-Non-neoplastic; AUS-Atypia of undetermined significance; BN-benign neoplasm; SUMP - salivary gland neoplasm of uncertain malignant potential; SM-suspicious for malignancy; M-Malignant.

Table 2 Most Common Benign and Malignant Salivary Gland Diagnoses in Each Category of the Milan System for Reporting Salivary Gland Cytopathology

\begin{tabular}{|c|c|c|}
\hline Category & Most common benign diagnosis & $\begin{array}{c}\text { Most common malignant } \\
\text { diagnosis }\end{array}$ \\
\hline 1.Non diagnostic & PA (2cases) and lipoma (2cases) & ACC (2cases) \\
\hline 2.Non neoplastic & Intra parotid lymphnode (5cases) & Lymphoma (1case) \\
\hline 3.Atypia of undetermined significance & Warthintumor (15 cases) & MEC ( 2 cases $)$ \\
\hline 4a.Benign neoplasm & PA (32 cases) & MEC (1 case) ACC ( 1 case) \\
\hline $\begin{array}{l}\text { 4b.Salivary gland neoplasm of } \\
\text { uncertain malignant potential }\end{array}$ & PA (12 cases) MEC (5 cases) & MEC (5cases) \\
\hline 5.Suspicious for malignancy & PA (2cases) & MEC ( 4 cases $)$ \\
\hline 6.Malignant & Warthintumor (1 case) & $\begin{array}{c}\text { SCC (primary and metastatic; } 9 \\
\text { cases) }\end{array}$ \\
\hline
\end{tabular}

Abbreviations: ACC — Adenoid cystic carcinoma; MEC—Mucoepidermoid carcinoma, PA—Pleomorphic adenoma, SCCSquamous cell carcinoma.'

Table 3 Cytological diagnostic categories of MSRSGC with illustrative examples

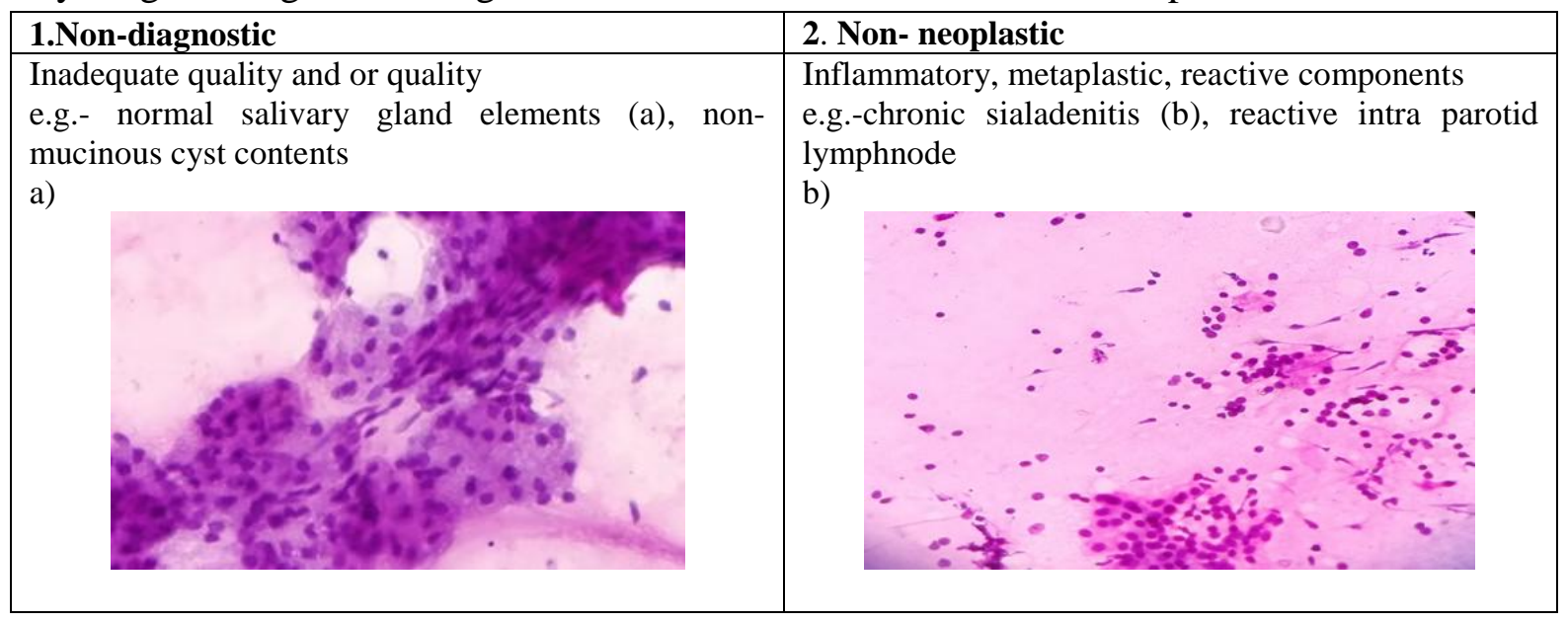



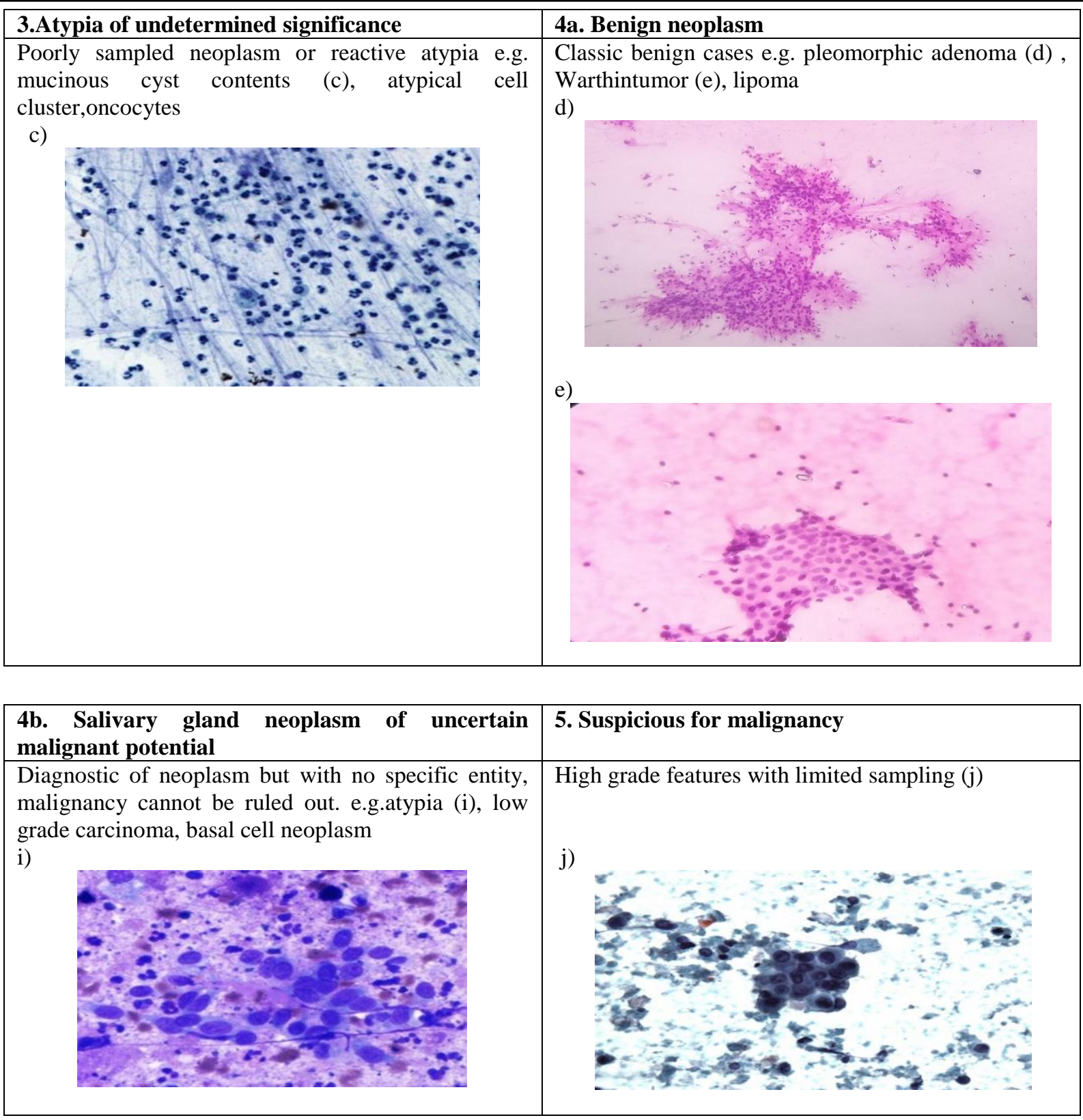

\section{Malignant}

Specific type and grade of malignancy (low grade and high grade), including metastases. Mucoepidermoid carcinoma (k), Adenoid cystic carcinoma (l), Acinic cell carcinoma

k)

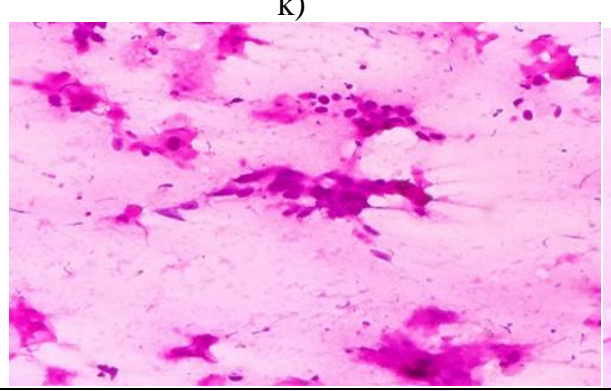

\section{Discussion}

Despite widespread acceptance of FNA as first line diagnostic approach in patients with salivary gland lesion, it remains one of the most
1)

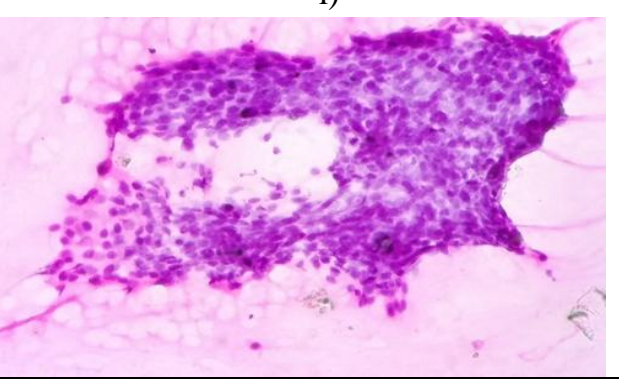

challenging areas within cytopathology $y^{6,8,9,20-25}$.

Hence there is a need for application of standardised system for reporting salivary gland FNA, which would help to optimise the clinical utility of this test. 
Similar to Bethesda system for reporting thyroid cytopathology, the MSRSGC represents a tiered classification system that provides diagnostic information, risk assessment, and management guidelines ${ }^{17}$. In this retrospective study, we found MSRSGC are fairly easy to adopt in daily practise.

In our study, we found $17.4 \%$ (62/356) of aspirates were non-diagnostic. Reason for not obtaining representative aspirate could be due to various reasons like improper positioning of the needle, haemorrhage and cystic areas within the tumor. Ultrasound guided FNA plays a major role in increasing diagnostic accuracy and reduce the chance of sampling errors in cases of repeat FNA for non-representative samples.

Overall on surgical follow-up majority of cases were benign $74.9 \%$ while $25.1 \%$ were malignant. Risk of malignancy for benign category was found to be compatible with $<5 \%$ rate as suggested by MSRSGC $^{27}$. Histological malignant cases under this category included adenoid cystic carcinoma (1) and carcinoma ex pleomorphic adenoma (1). According to recent literature review, cases such as carcinoma ex pleomorphic adenoma, mucoepidermoid carcinoma, and adenoid cystic carcinoma could be miscategorised under benign category. Adenoid cystic carcinoma could mimic pleomorphic adenoma on FNA due to shared cellular and matrix components, and when mucoid material in case of pleomorphic adenoma take the shape of hyaline globule it can be confused for adenoid cystic carcinoma ${ }^{30}$. Malignant component in case of Carcinoma ex pleomorphic adenoma can be missed due to inadequate sampling giving it a false impression of benign lesion on FNA.

95.2\% risk of malignancy for malignant category in our study was found concordant with above 90\% ROM as suggested by MSRSGC. One case of Warthin tumor had been falsely diagnosed under malignant category on FNA, for which the probable reason could be squamous metaplasia and dirty background in a Warthintumor, giving it a false impression for squamous cell carcinoma or mucoepidermoid carcinoma.
Under the indeterminate categories, SM category carried $66.7 \%$ ROM which varies widely from institution to institution ranging from $58.6 \%$ to $100 \%$ based on variability of pathologist's experience and their practices ${ }^{2925,}{ }^{30-32}$.The SUMP category had $100 \%$ and $31 \%$ risk of neoplasm and risk of malignancy respectively. This ROM is found compatible with $35 \%$ target rate given by MSRSGC. $13.5 \%$ cases were included under AUS category which was found to be slightly higher compared to $<10 \%$ recommendation given by MSRSGC. The AUS category carried a $66.7 \%$ risk of neoplasm and $14.2 \%$ risk of malignancy, in line with 20\% ROM given by MSRSGC ${ }^{27}$.

Milan system also provides management guidelines, under which non-neoplastic category were monitored without surgical follow-up whereas atypical to malignant category had surgical follow-up.

The major limitation of our study is its retrospective nature, which might lead to bias in assigning cases according to the Milan system, particularly when histologic follow-up was already known. However due to limited acceptance of the Milan system in most of the institutions, retrospective study remains to be the main mode of assessing this study.

\section{Conclusion}

The recently proposed MSRSGC represents a standardised method for reporting salivary gland FNA. It is a uniform system accepted internationally for reporting salivary gland FNA. It helps to bring in better communication between cytopathologists and treating clinicians also between institutions, thus result in overall improved patient care. However, larger studies with clinical follow-up are required to determine the overall accuracy of MSRSGC.

\section{References}

1. Seethala RR, Li Volsi VA, Baloch ZW. Relative accuracy of fine needle aspiration and frozen section in the diagnosis of 
lesions of the parotid gland. Head Neck.2005;27:217-223.

2. Viswanathan K, Sung S et al. The role of the Milan System for Reporting Salivary Gland Cytopathology: a 5-year institutional experience [published online ahead of print May 24, 2018].

3. Wang H, Fundakowski C, Khurana JS, Jhala N. Fine-needle aspiration biopsy of salivary gland lesions. Arch Pathol Lab Med. 2015; 139:1491-1497.

4. Goyal S, Sharma S, Diwaker P. Diagnostic role and limitations of FNAC in oral and jaw swellings. Diagn Cytopathol.2015; 43:810-818.

5. Fakhry N, Antonini F, Michel J, et al. Fineneedle aspiration cytology in the management of parotid masses: evaluation of 249 patients. Eur Ann Otorhinolaryngol Head Neck Dis.2012;129:131-135.

6. Layfield LJ, Glasgow BJ. Diagnosis of salivary gland tumors by fine-needle aspiration cytology: a review of clinical utility and pitfalls. Diagn Cytopathol. 1991;7:267-272.

7. Kocjan G, Nayagam M, Harris M. Fine needle aspiration cytology of salivary gland lesions: advantages and pitfalls. Cytopathology.1990;1:269-275.

8. Jayaram N, Ashim D, Rajwanshi A, Radhika S, Banerjee CK. The value of fineneedle aspiration biopsy in the cytodiagnosis of salivary gland lesions. Diagn Cytopathol.1989;5:349-354.

9. Mondal A, Das MM, Mukherjee PK. Fine needle aspiration biopsy cytology in diagnosis of salivary gland tumours. J Indian Med Assoc. 1989;87:108-110.

10. Schmidt RL, Hall BJ, Wilson AR, Layfield LJ. A systematic review and meta-analysis of the diagnostic accuracy of fine-needle aspiration cytology for parotid gland lesions. Am J ClinPathol. 2011;136(1): 4559.
11. Layfield LJ. Fine-needle aspiration in the diagnosis of head and neck lesions: a review and discussion of problems in differential diagnosis. Diagn Cytopathol. 2007;35 (12): 798-805.

12. Layfield LJ, Gopez E, Hirschowitz S. Cost efficiency analysis for fineneedle aspiration in the workup of parotid and submandibular gland nodules. Diagn Cytopathol. 2006;34(11):734-738.

13. Liu CC, Jethwa AR, Khariwala SS, Johnson J, Sensitivity SJJ. Specificity, and posttest probability of parotid fine-needle aspiration: a systematic review and metaanalysis. Otolaryngol Head Neck Surg. 2016; 154(1):9-23.

14. Rossi ED, Faquin WC, Baloch Z, et al. The Milan System for Reporting Salivary Gland Cytopathology: Analysis and suggestions of initial survey. Cancer Cytopathol 2017;125(10):757-766.

15. Song JS, Shafique K, Wong QL, LiVolsi AV, Montone TK, Baloch Z. The utility of the Milan system as a risk stratification tool for salivary gland fine needle aspiration cytology specimens. Clinical cytojan 2019 [Epub ahead of print]

16. Ali SZ, Cibas E,eds. The Bethesda System for Reporting Thyroid Cytopathology: Definitions, Criteria and Explanatory Notes. 1sted. New York: Springer US; 2010.

17. Jain R, Gupta R, Kudesia M, Singh S. Fine needle aspiration cytology in diagnosis of salivary gland lesions: A study with histologic comparison. Cyto Journal 2013;10:5.

18. Schindler S, Nayar R, Dutra J, Bedrossian CW. Diagnostic challenges in aspiration cytology of the salivary glands. Semin Diagn Pathol 2001;18(2):124-146.

19. Ashraf A, Shaikh AS, Kamal F, Sarfraz R, Bukhari MH. Diagnostic reliability of FNAC for salivary gland swellings: a comparative study. Diagn Cytopathol 2010;38(7):499-504. 
20. Layfield LJ, Tan P, Glasgow BJ. Fineneedle aspiration of salivary gland lesions. Comparison with frozen sections and histologic findings. Arch Pathol Lab Med. 1987;111:346-353.

21. Behzatoglu K, Bahadir B, Kaplan HH, Yucel Z, Durak H, Bozkurt ER. Fine needle aspiration biopsy of the parotid gland. Diagnostic problems and 2 uncommon cases. Acta Cytol. 2004; 48:149-154.

22. Mukunyadzi P. Review of fine-needle aspiration cytology of salivary gland neoplasms, with emphasis on differential diagnosis. Am J ClinPathol. 2002;118 (suppl): S100-S115.

23. Boccato P, Altavilla G, Blandamura S. Fine needle aspiration biopsy of salivary gland lesions. A reappraisal of pitfalls and problems. ActaCytol. 1998;42:888-898.

24. Cajulis RS, Gokaslan ST, Yu GH, FriasHidvegi D. Fine needle aspiration biopsy of the salivary glands. A five-year experience with emphasis on diagnostic pitfalls. ActaCytol. 1997;41:14121420.

25. Cardillo MR. Salivary gland masses: the diagnostic value of fineneedle aspiration cytology. Arch Anat Cytol Pathol. 1990;38: 26-32.

26. Thiryayi SA, Low YX, Shelton D, Narine N, Slater D, Rana DN. A retrospective 3year study of salivary gland FNAC with categorisation using the Milan reporting system. Cytopathol 2018. [Epub ahead of print]

27. Pusztaszeri M, Baloch Z, Vielh P, Faquin WC. Application of the Milan system for reporting risk stratification in salivary gland cytopathology. Cancer Cytopathol 2018;126 (1):69-70.

28. Salehi S, Maleki Z. Diagnostic challenges and problem cases in salivary gland cytology: A 20-year experience. Cancer Cytopathol 2018;126(2):101-111.

29. Hughes JH, Volk EE, Wilbur DC, Cytopathology Resource Committee CoAP.
Pitfalls in salivary gland fine-needle aspiration cytology: lessons from the College of American Pathologists Interlaboratory Comparison Program in Nongynecologic Cytology. Arch Pathol Lab Med 2005;129(1):26-31.

30. Maleki Z, Miller JA, Arab SE, et al. "Suspicious" salivary gland FNA: Risk of malignancy and interinstitutional variability. Cancer Cytopathol 2018;126 (2):94-100.

31. Rossi ED, Wong LQ, Bizzarro T, et al. The impact of FNAC in the management of salivary gland lesions: Institutional experiences leading to a risk-based classification scheme. Cancer Cytopathol 2016;124(6):388-396.

32. Layfield LJ, Baloch Z, Hirschowitz SL, Rossi ED. Impact on Clinical Follow-up of the Milan System for Salivary Gland Cytology: A Comparison with a Traditional Diagnostic Classification. Cytopathol 2018. [Epub ahead of print]. 